\title{
Gambaran Tingkat Pengetahuan lbu Postpartum Primipara tentang Perawatan Payudara di Puskesmas Saronggi
}

\author{
Fitriah1, Yulia Wardita. ${ }^{2}$, Herlina Alvianti Ningsih ${ }^{3}$ \\ 1,Program Studi Sarjana Kebidanan Universitas Wiraraja Madura \\ ${ }^{2,3}$ Program Studi Profesi Kebidanan Universitas Wiraraja Madura \\ fitriah.fik@wiraraja.ac.id*,2yulia.fik@wiraraja.ac.id, ${ }^{3}$ herlina.fik@wiraraja.ac.id \\ *Corresponding author
}

\section{Informasi artikel \\ Sejarah artikel: \\ Received: 16-04-2020 \\ Revised: 27-05-2020 \\ Accepted :30-05-2020}

Kata kunci:
Pengetahuan
Postpartum
Perawatan payudara

\begin{abstract}
ABSTRAK
Pengetahuan ibu post partum primipara tentang perawatan payudara masih sangat rendah. Berdasarkan studi pendahuluan di Puskesmas Saronggi, terhadap 4 ibu post partum khususnya primipara didapatkan ibu tersebut tidak mengetahui tentang perawatan payudara sehingga banyak terjadi masalah dalam proses menyusui seperti, mengalami air susu yang tidak keluar, mengalami puting susu yang masuk kedalam, megalami puting susu yang tidak bersih, megalami nyeri saat menyusui. Untuk mencegah terjadinya masalah tersebut dengan melakukan perawatan payudara.Tujuan penelitian adalah untuk mengetahui gambaran tingkat pengetahuan ibu postpartum primipara tentang perawatan payudara di Puskesmas Saronggi.Jenis penelitian ini adalah Deskriptif dengan pendekatan cross sectional. Populasi dalam penelitian ini adalah seluruh ibu postpartum primipara yang tercatat di Puskesmas Saronggi pada bulan 13 Januari-13 Februari 2020 sebanyak 30 orang. Teknik sampling yang digunakan yaitu non probability sampling dengan metode accidental sampling. Analisa data dalam penelitian ini menggunakan uji univariat. Hasil dari penelitian yaitu seluruh ibu postpartum primipara di Puskesmas Saronggi berusia 20-35 tahun sebesar $100 \%$, sebagian besar ibu postpartum primipara berpendidikan SMA sebesar $53,3 \%$, sebagian besar ibu postpartum primipara adalah IRT sebesar $83,3 \%$ dan Sebagian besar ibu postpartum primipara memiliki pengetahuan kurang tentang perawatan payudara sebesar 40\%. Dapat disimpulkan bahwa sebagian besar ibu postpartum primipara di Puskesmas Saronggi memiliki pengetahuan kurang tentang perawatan payudara. Saran yaitu diharapkan ibu postpartum dapat menambah informasi dan meningkatkan pengetahuan tentang perawatan payudara sehingga dapat mencegah terjadinya masalah menyusui.
\end{abstract}

\section{ABSTRACT}

Key word:

Knowledge

Postpartum

breastcare

\begin{abstract}
Primipara's post partum maternal knowledge about breast care is still very low. Based on a preliminary study at the Saronggi Health Center, four post partum mothers, especially primipara, found that the mother did not know about breast care, so there were many problems in the process of breastfeeding, such as experiencing milk that did not come out, having nipples that went into, experiencing nipples that did not clean, experience pain when breastfeeding. To prevent these problems by taking care of the breast. The purpose of this study was to determine the level of knowledge of primiparous postpartum mothers about breast care in the Saronggi Community Health Center. This type of research is descriptive with cross sectional approach. The population in this study were all primiparous postpartum mothers registered at the Saronggi Community Health Center on January 13-February 132020 by 30 people. The sampling technique used is non probability sampling with accidental sampling method. Analysis of the data in this study used a univariate test. The results of the study are all primiparous postpartum mothers at Saronggi Puskesmas aged 20-35 years by $100 \%$, most primiparous postpartum mothers with high school education were $53.3 \%$, most primiparous postpartum mothers were IRT $83.3 \%$ and most postpartum mothers Primipara has less knowledge about breast care by $40 \%$.
\end{abstract}


it can be concluded that the majority of primiparous postpartum mothers in Puskesmas Saronggi have less knowledge about breast care. Suggestions are expected that postpartum mothers can add information and increase knowledge about breast care so as to prevent breastfeeding problems.

\section{PENDAHULUAN}

Post partum adalah keadaan ibu setelah melahirkan bayi dan keluarnya plasenta sampai kembali normalnya kondisi alat reproduksi seperti sebelum hamil yang berlangsung selama 40 hari atau sekitar 6 minggu. (Marliandani, 2015). Tahapan pada masa nifas ini meliputi : perubahan fisik, psikis dan lochea baik yang terjadi secara fisologis maupun patologis.(Walyani, 2015). Dalam masa nifas terdapat juga beberapa komplikasi dan penyakit yang meliputi: Beberapa masalah yang sering terjadi pada saat puerperium meliputi : infeksi masa nifas, infeksi saluran kemih, metritis, bendungan payudara, infeksi payudara, abses payudara, abses pelvis,peritonitis, infeksi luka perineum, infeksi luka abnominaldan perdarahan pervaginam. (Marliandani, 2015; Wulandari, 2012)

Terjadinya bendungan ASI karena adanya penyempitan pada saluran ASI (duktus laktiferus, yang disebabkan oleh let down reflek yang lemah karena ibu tidak menyusui secara optimal sehingga ASI. mengental dan menyumbat kelenjar ASI. Payudara akan terasa lebih penuh, panas, keras, dan nyeri pada perabaan, disertai kenaikan suhu tubuh.(Marliandani, 2015). payudara yang bengkak pada Ibu nifas yang menyusui sering dianggap sebagai rasa sakit sakit biasa dan tidak perlu dikhawatirkan (Suprayitno, 2018)

Penyebab terjadinya infeksi payudara adalah bakteri staphylococcus aureus. Ini terjadi karena adanya luka pada puting sehingga staphyloccus masuk melalui luka tersebut pada peredaran darah di payudara.(Walyani, 2015). Tahun 2015 di Amerika Serikat sebanyak 6543 ibu menyusui mengalami infeksi payudara (WHO, 2015). Sedangkan di Indonesia pada tahun yang sama ibu menyusui yang menglami infeksi payudara sebesar 77.231 atau (37, 12 \%).(Ulfah, 2018). Tahun 2012 post partum yang mengalami infeksi payudara sebesar 77.231 atau $(37,12 \%)$. (Pusdatin, 2017). Hasil penelitian salat 2019 menyebutkan bahwa kelancaran ASI berhubungan dengan kecemasan ibu. Untuk mencegah terjadinya bendungan ASI dan mastitis adalah dengan melakukan berast care. Perawatan payudara (breast care) adalah kegiatan merawat payudara pada saat masa nifas dengan langkah langkah tertentu yang sudah ditetapkan oleh kemenkes. Hal ini dilakukan untuk memperlancar pengeluaran ASI (Lockhart, 2014). Menurut peneliti sebelumnya supaya produksi ASI lancar dan tidak terjadi bendungan ASI perawatan payudara sangat penting dilakukan, selain melakukan breast care ibu menyusui harus banyak mengkonsumsi makanan yang bergizi dan harus selalu menyusui bayinya sesering mungkin karena dengan adanya let down reflex dapat membantu melancarkan pengeluaran ASI. (Rosita, 2017). Studi pendahuluan pada tanggal 2-6 Januari 2020 di Puskesmas Saronggi, terhadap 4 ibu post partum khususnya primipara didapatkan ibu post partum primipara tidak mengetahui tentang perawatan payudara sehingga banyak terjadi masalah yang sering dialami oleh ibu post partum primipara dalam proses menyusui seperti, megalami air susu yang tidak keluar, mengalami puting susu yang masuk kedalam, megalami puting susu yang tidak bersih, megalami nyeri saat menyusui.

\section{METODELOGI PENELITIAN}

Riset ini menggunakan jenis penelitian deskriptif. Sedangkan rancangan penelitian menggunakan rancangan cross sectional. Populasi penelitian ini yaitu seluruh ibu postpartum primipara yang tercatat di Puskesmas Saronggi pada bulan Januari 2020 sebanyak 30 orang. Sampel pada riset ini adalah seluruh ibu postpartum primipara yang berkunjung di Puskesmas Saronggi pada tanggal 13 Januari-13 Februari 2020. Tehnik pengambilan sampel yang digunakan adalah non probability sampling dengan metode accidental sampling. Untuk analisa datanya menggunakan uji analisis univariat.

\section{HASIL PENELITIAN}

\section{A. DATA UMUM}

1. Karakteristik Responden berdasarkan usia

\begin{tabular}{ccc}
\hline Usia Responden & $\mathrm{F}$ & $\%$ \\
\hline$<\mathbf{2 0}$ tahun & 0 & 0 \\
\hline $\mathbf{2 0 - 3 5}$ tahun & 30 & 100 \\
\hline$>35$ tahun & 0 & 0 \\
\hline Jumlah & 30 & 100 \\
\hline
\end{tabular}


Dari tabel diatas menerangkan bahwa seluruh Responden va berusia 20-35 tahun sebanyak 30 ibu (100\%).

2. Karakteristik berdasarkan pendidikan

\begin{tabular}{ccc}
\hline Pendidikan & F & (\%) \\
\hline Tidak Sekolah & 0 & 0 \\
\hline SD & 6 & 20 \\
\hline SMP/ Sederajat & 6 & 20 \\
\hline SMA/ Sederajat & 16 & 53,3 \\
\hline Perguruan Tinggi & 2 & 6,7 \\
\hline Jumlah & 30 & 100 \\
\hline
\end{tabular}

Dari tabel diatas menerangkan bahwa sebagian besar Responden lulus pendidikan SMA sebanyak 16 orang $(53,3 \%)$ dan paling sedikit lulus
Akademi/Perguruan Tinggi sebanyak 2 orang $(6,7 \%)$.

3. Karakteristik Responden berdasarkan pekerjaan

\begin{tabular}{ccc}
\hline Pekerjaan & F & \% \\
\hline IRT & 25 & 83,3 \\
\hline PNS & 2 & 6,7 \\
\hline $\begin{array}{c}\text { Pegawai } \\
\text { Kontrak }\end{array}$ & 3 & 10 \\
\hline Jumlah & 30 & 100 \\
\hline
\end{tabular}

Sumber : Data Primer, 2020

Dari tabel diatas menerangkan bahwa paling banyak Responden nya adalah IRT sebanyak 25 orang $(83,3 \%)$ dan paling sedikit bekerja sebagai PNS sebanyak 2 orang $(6,7 \%)$.

\section{B. DATA KHUSUS}

1. Pengetahuan

\begin{tabular}{ccc}
\hline Pengetahuan & Frekuensi & Presentase (\%) \\
\hline Baik & 11 & 36,7 \\
\hline Cukup & 7 & 23,3 \\
\hline Kurang & 12 & 40 \\
\hline Jumlah & 30 & 100 \\
\hline
\end{tabular}

Sumber : Data Primer, 2020

Tabel diatas menerangkan bahwa terbanyak Responden berpengetahuan

orang (40\%) dan terendah, berpengetahuan kurang tentang breast care sebanyak 12

cukup sebanyak 7 orang $(23,3 \%)$

2. Tabulasi silang Usia dengan pengetahuan ibu postpartum primipara tentang perawatan payudara

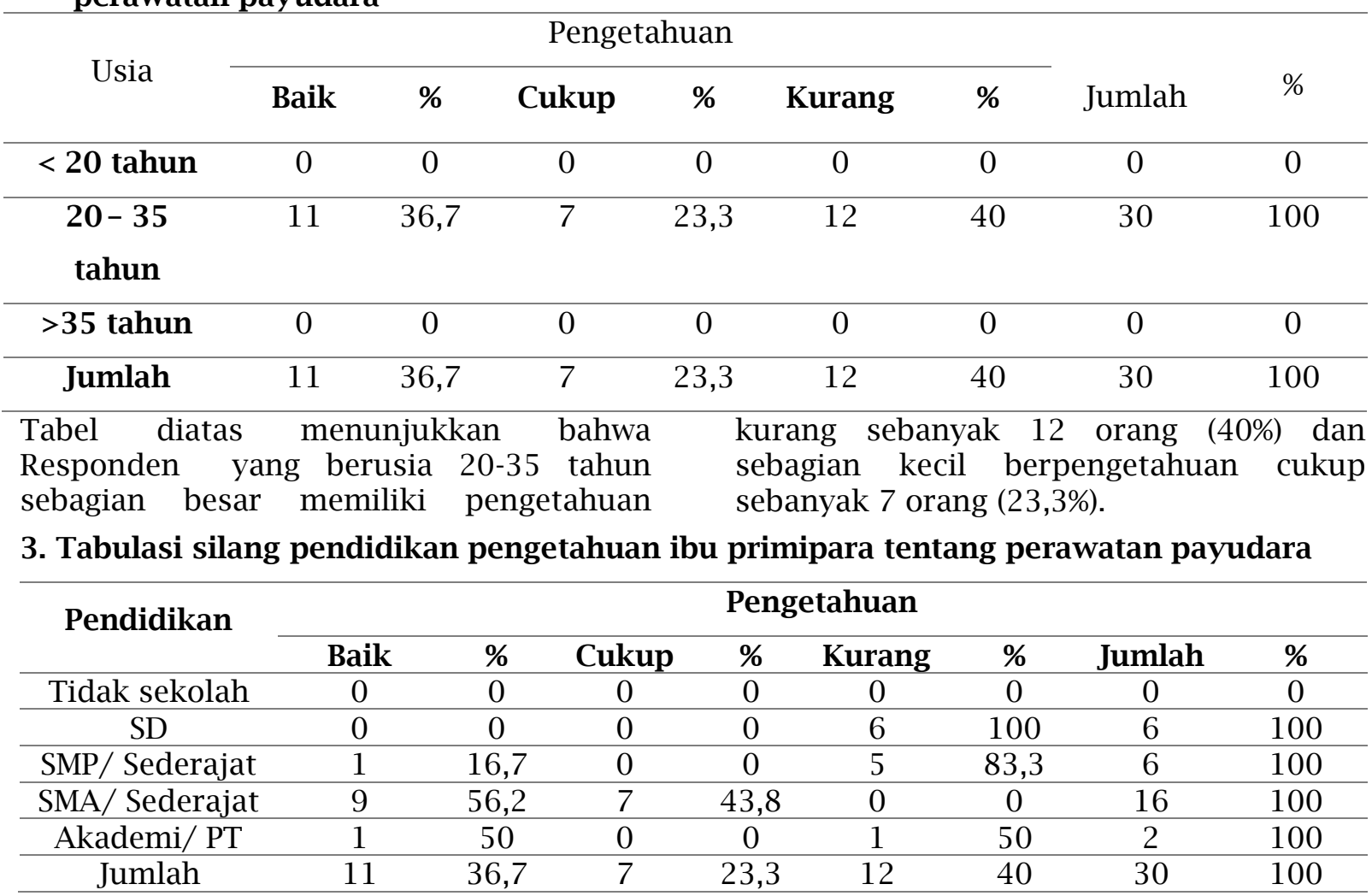

27 | Journal Of Health Science 
Sumber : Data Primer, 2020

Tabel diatas menunjukkan bahwa Responden yang sudah menempuh pendidikan SD seluruhnya berpengetahuan kurang sebanyak 6 orang (100\%). Responden yang sudah menempuh pendidikan SMP terbanyak berpengetahuan kurang sebanyak 5 orang $(83,3 \%)$ dan terendah Responden berpengetahuan baik sebanyak 1 orang (16,7\%). Responden dengan pendidikan lulus SMA terbanyak berpengetahuan baik sebanyak 9 orang $(56,2 \%)$ dan terendah berpengetahuan cukup sebanyak 7 orang (43,8\%). Responden yang lulus pendidikan akademi/perguruan tinggi sebagian berpengetahuan baik sebanyak 1 orang (50\%) dan berpengetahuan kurang sebanyak 1 orang (50\%)

\section{Pekerjaan dengan pengetahuan ibu primipara tentang perawatan payudara.}

\begin{tabular}{ccccccccc}
\hline \multirow{2}{*}{ Pekerjaan } & \multicolumn{8}{c}{ Pengetahuan } \\
\cline { 2 - 10 } & Baik & \% & cukup & \% & kurang & \% & Jumlah & \% \\
\hline IRT & 8 & 32 & 6 & 24 & 11 & 44 & 25 & 100 \\
\hline PNS & 1 & 50 & 0 & 0 & 1 & 50 & 2 & 100 \\
\hline Pegawai Kontrak & 2 & 66,7 & 1 & 33,3 & 0 & 0 & 3 & 100 \\
\hline Jumlah & 11 & 36,7 & 7 & 23,3 & 12 & 40 & 30 & 100 \\
\hline
\end{tabular}

Sumber : Data Primer, 2020

Tabel diatas menerangkan bahwa Responden yang bekerja sebagai IRT terbanyak berpengetahuan kurang sebanyak 11 orang (44\%) dan terendah berpengetahuan cukup sebanyak 6 orang (24\%). Responden yang bekerja sebagai PNS sebagian berpengetahuan baik sebanyak 1 orang (50\%) dan berpengetahuan kurang sebanyak 1 orang (50\%). Responden yang bekerja sebagai pegawai kontrak terbanyak berpengetahuan baik sebanyak 2 orang $(66,7 \%)$ dan terndah berpengetahuan cukup sebanyak 1 orang $(33,3 \%)$

\section{PEMBAHASAN}

A. Usia dengan pengetahuan ibu postpartum primipara tentang perawatan payudara di Puskesmas Saronggi

Hasil penelitian memperlihatkan bahwa Responden yang berusia 20-35 tahun sebagian besar berepengetahuan kurang sebanyak 12 orang (40\%) dan sebagian kecil berpengetahuan cukup sebanyak 7 orang (23,3\%).

Menurut peneliti, usia dapat menggambarkan pemahaman ibu tentang berast [ care, dimana dalam hasil penelitian ini ibu yang berpengetahuan baik mayoritas pada ibu yang berusia 20- 35 tahun. Karena dengan bertambahnya usia seorang ibu mempengaruhi juga pandangan akan pentingnya kesehatan untuk diri sendiri melalui mencari informasi lewat media sosial supaya pemahamannya meningkat. Menurut peneliti sebelumnya menyatakan bahwa usia mempengaruhi ingatan dan pandangan, semakin bertambah usia seseorang semakin matang wawasannya sehingga kompetensi yang diperoleh semakin membaik. (Wibowo \& Rahayuningsih, 2017)

\section{B. Pendidikan dengan keterampilan ibu Postpartum primipara tentang perawatan payudara di Puskesmas Saronggi}

Hasil penelitian memperlihatkan Responden dengan lulus pendidikan SD seluruhnya memiliki pemahaman kurang sebanyak 6 orang (100\%). Responden yang lulus pendidikan SMP sebagian besar memiliki pemahaman kurang sebanyak 5 orang $(83,3 \%)$ dan memiliki pemahaman baik sebanyak 1 orang (16,7\%). Responden yang lulus pendidikan SMA memiliki pemahaman baik sebanyak 9 orang $(56,2 \%)$ dan memiliki pemahaman cukup sebanyak 7 orang (43,8\%). Responden yang sudah menempuh pendidikan akademi/perguruan tinggi memiliki pemahaman baik sebanyak 1 orang (50\%) dan sebagian memiliki pemahaman kurang sebanyak 1 orang (50\%).

Menurut peneliti pendidikan menggambarkan wawasan ibu tentang breast care. Ibu yang memiliki pemahaman kurang adalah yang sudah menepuh pendidikan SD. Hal ini disebabkan karena ibu merasa kesulitan dalam menerima informasi Pendidikan pada seseorang 
sangatlah mempengaruhi wawasannya karena semakin tinggi tingkat pendidikan seseorang berdampak pula pada wawasannya. Hal ini juga diungkapkan oleh penliti lain, bahwa orang yang sudah menempuh pendidikan tinggi mempunyai keinginan besar untuk mengetahui dan melakukan breast care, dimana breast care yang sangat bermanfaat untuk kelancaran pengeluaran ASI. (Wibowo \& Rahayuningsih, 2017).

\section{Pekerjaan dengan pengetahuan ibu Postpartum primipara tentang perawatan payudara}

Hasil penelitian memperlihatkan Responden yang bekerja sebagai IRT memiliki wawasan kurang sebanyak 11 orang (44\%) dan memiliki wawasan cukup sebanyak 6 orang (24\%). Responden yang bekerja sebagai PNS sebagian memiliki wawasan baik sebanyak 1 orang (50\%) dan sebagian memiliki pemahaman kurang sebanyak 1 orang (50\%). Responden yang bekerja sebagai pegawai kontrak memiliki pemahaman yang baik sebanyak 2 orang $(66,7 \%)$ dan memiliki pemahaman yang cukup sebanyak 1 orang (33,3\%).

Menurut peneliti pekerjaan seseorang menggambarkan wawasan ibu juga tentang perawatan payudara. Seseorang bekerja tujuannya adalah untuk mencapai suatu keadaan yang lebih baik. Pada penelitian ini sebagian besar ibu yang tidak bekerja memiliki pengetahuan yang kurang. Hal ini dikarenakan kegiatan ibu sehari-hari yaitu melakukan pekerjaan rumah tangga, sehingga interaksi dengan orang lain masih kurang sehingga ibu kurang update dalam bertukar. Sedangkan wanita atau ibu yang bekerja cenderung lebih update dalam memperoleh informasi dari teman-temannya dikantor, sehingga dapat menambah wawasan dari ibu tersebut.

\section{Tingkat Pengetahuan Ibu Postpartum Primipara tentang Perawatan Payudara di Puskesmas Saronggi}

Hasil penelitian memperlihatkan bahwa ibu postpartum primipara di Puskesmas Saronggi memiliki pemahaman yang kurang tentang perawatan payudara sebanyak 12 orang (40\%) dan memiliki pemahaman yang cukup sebanyak 7 orang (23,3\%).Opini dari peneliti, pengetahuan ibu dipengaruhi juga oleh pikiran kritis dan pengalaman. Sesuatu yang pernah dialami oleh seseorang akan menjadi sebuah informasi. Pengalaman adalah salah satu wawasan yang telah dilalui oleh seseorang, sehingga pengalaman pribadi dapat digunakan sebagai pemahaman dari seseorang. Responden pada penelitian ini merupakan primipara dimana mereka baru pertama menjadi ibu nifas, sehingga pemahaman mereka masih belum kompeten terkait masa nifas.

\section{KESIMPULAN}

Kesimpulan dari riset ini adalah bahwa ibu yang berusia 20-35 dan sebagai ibu rumah tangga (IRT) memiliki pengetahuan yang kurang terkait perawatan payudara pada masa nifas. Sedangkan ibu postpartum dengan latar belakang pendidikan sekolah menengah atas (SMA) memiliki pengetahuan yang cukup terkait breast care payudara.

\section{DAFTAR PUSTAKA}

Ambarwati, 2010. Asuhan Kebidanan Nifas. Yogyakarta: Nuha Medika

Anggraini, 2013. Kejadian mastitis. Yogyakarta: Rohima Press

Azkah, 2012. Perawatan payudara (breast care). Jakarta: Azka Press

Depkes. R.I., 2013. Riset Kesehatan Dasar 2013. Jakarta: Badan Penelitian dan Pengembangan Kesehatan RI..

Dinkes Kab.Sumenep, 2018. Profil Kesehatan Kabupaten Sumenep Tahun 2017.

Heriyanto, Bambang, 2012. Metode Penelitian Kuantitatif. Surabaya: PMN.

Hidayat, A. Aziz Alimul, 2010. Metode Penelitian Kebidanan dan Teknik Analisa Data. Jakarta: Salemba Medika.

Kalia, 2012. Masalah-masalah ibu menyusui. Jakarta: Mitra Setia

Kementrian Kesehatan RI, 2015. Profil Kesehatan Indonesia 2015. Jakarta: Kementrian Kesehatan RI.

Lockhart, dkk, 2014. Masa Nifas Fisiologi \& Patologi. Tangerang Selatan: PT. Binarupa Aksara

Mochtar, Rustam. 2011. Sinopsis Obstetri, Obstetri Fisiologi, Obstetri Patologis, Jilid I, Jakarta : EGC

Notoatmodjo, Soekidjo, 2010. Metodologi penelitian. Jakarta: Rineka Cipta.

Notoatmodjo, Soekidjo, 2010. Promosi Kesehatan dan Teori Aplikasi. Jakarta: Rineka Cipta. 
Prisilia, 2012. Perawatan payudara ibu postpartum. Yogyakarta: Nuha Medika

Rukiyah, Ai Yeyeh, dkk., 2010. Asuhan Neonatus, Bayi dan Anak Balita. nJakarta : Trans Info Media

Salat, S. Y. S., \& Suprayitno, E. (2019). HUBUNGAN KECEMASAN IBU MENYUSUI DENGAN KELANCARAN PENGELUARAN AIR SUSU IBU (ASI) DI BPS KERTA TIMUR KECAMATAN DASUK KABUPATEN SUMENEP. Jurnal Ilmiah Kebidanan (Scientific Journal of Midwifery), 5(2), 51-56.

Suprayitno, E., Pratiwi, I. G. D., \& Yasin, Z. (2018). GAMBARAN PENYEBAB TERJADINYA PEMBENGKAKAN PAYUDARA PADA IBU MENYUSUI DI POLINDES DESA MEDDELEN KECAMATAN LENTENG. WIRARAJA MEDIKA, 8(1), 13-18.

Marliandani, dkk, 2015. Asuhan Kebidanan Pada Masa Nifas dan Meyusui. Jakarta:Salemba Medika

Walyani, dkk. 2015. Asuhan Kebidanan Masa Nifas dan Menyusui. Yogyakarta: Salemba Medika : Pustaka Baru Press 